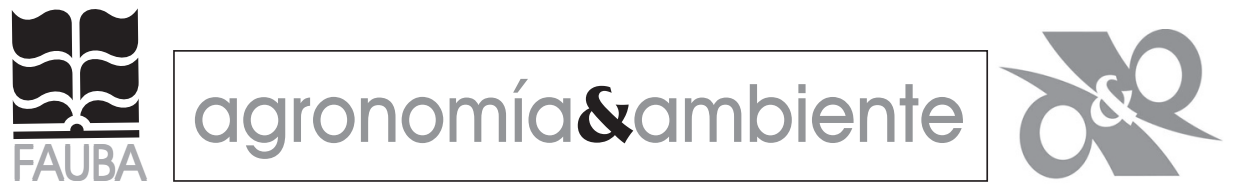

\title{
THE HONEST BROKER; MAKING SENSE OF SCIENCE IN POLICY AND POLITICS
}

\author{
Pielke, Roger A. Jr.
}

(2007) 188pp, Cambridge University Press, NY. ISBN 978-0-521-69481-0

Recibido: $15-10-12$

Aceptado 22-10-12

RESEÑA

The Honest Broker; Making Sense of Science in Policy and Politics es un libro con un claro interés didáctico. Roger Pielke Jr es un joven profesor de Ciencias Ambientales de la Universidad de Colorado (EEUU) que se ha dedicado al análisis de los debates públicos frente al cambio climático. Como resultado de su trabajo sobre las formas en que la ciencia y la política interactúan, aquí presenta un esquema idealizado de los roles que puede tomar un científico o profesional como experto en la toma de decisiones en el mundo real. Dos de estos roles posibles, básicamente pasivos, resultan los más familiares y son los del científico puro, que produce información sin otro propósito que el de avanzar en el grado de conocimiento y deja en manos del resto de la sociedad su posible aplicación, y el del científico o profesional consultor ('árbitro'), que ofrece respuestas expertas en el contexto de consultas concretas acerca del modo de acción más conveniente entre un conjunto de alternativas.

La obra propone dos roles más activos, que dan lugar a una discusión más profunda y necesaria en relación a los dilemas ambientales de la sociedad. Por un lado, el del "issue advocate", que según su filiación nosotros llamaríamos miembro de un lobby (para entidades con fines de lucro), o activista (ONGs), un rol valioso cuando se ejerce con honestidad pero mucho menos constructivo cuando se cumple en forma encubierta bajo la etiqueta de alguna de las dos formas pasivas anteriores. Es decir, cuando bajo la apariencia de objetividad se usa selectivamente la información para apoyar un determinado curso de acción (como antídoto, véanse las buenas prácticas propuestas por Marcos Méndez en 'Ecosistemas', 19: 66-68; 2010). Por otro lado, el rol activo abiertamente defendido por Pielke, es el que llama proveedor de alternativas ('bróker honesto'). Como su nombre lo indica, y a diferencia de los roles anteriores (especialmente los de consultor-árbitro y activistalobbyist), el proveedor de alternativas apunta a hacer consciente a quien lo consulta de la existencia de un rango amplio de opciones, o en todo caso, si no las hubiere, a expandir su perspectiva para que pueda tomar una mejor decisión basándose en sus preferencias y valores.

Los dos roles pasivos están asociados con lo que se conoce como el modelo lineal de la ciencia, en el que hemos sido instruidos la mayoría de los profesionales con formación científica en algún momento: el supuesto flujo de información de la ciencia básica a la aplicada, luego al desarrollo tecnológico, y finalmente al beneficio para la sociedad. Esto de ningún modo sucede así; en palabras del propio autor: "...science... can and frequently does point to the existence of a problem that compels action, but introducing reasons ... is quite different from providing guidance on what actions to actually take..." (Ver el debate que, en nuestro ámbito, han mantenido al respecto Diego Gurvich et al. y José Paruelo en Ecología Austral, 19: 255-258; 2009). Lo que no es tan obvio es el vínculo, hecho explícito en el libro, entre el modelo lineal y la idea de que el consenso científico es un prerrequisito para el consenso político necesario para la acción. Pielke también considera esto erróneo, particularmente cuando se usa bajo el rol de lobista encubierto: el uso tendencioso de las incertezas científicas para oponerse a la acción. El proveedor de alternativas, en cambio, no ignora la complejidad del mundo real (ni la diversidad de visiones disciplinares, metodológicas, institucionales e ideológicas del sub-mundo científico), sino que lo presenta en su variedad y riqueza de un modo que sirva al propósito de tomar decisiones sobre una base más sólida.

Uno de los mensajes más potentes del libro es que cuanto mayor sea la incertidumbre científica, más importante es enfocarse en el abanico de decisiones posibles, y que en el marco de éstas, raramente la información científico-técnica es suficiente ya que entran en juego intereses y valores. En un extremo, cuando las posiciones 
son irreductibles, la información pasa a ser irrelevante (Pielke lo ilustra con los debates sobre el aborto). En el otro extremo, si hay valores compartidos en la sociedad y la información científica tiene amplio consenso, se aplicaría el modelo lineal (su ejemplo es el de un alerta de tornado). En los casos intermedios, los más frecuentes, el proveedor de alternativas jugaría el papel crucial de hacer la conexión entre las opciones políticamente realistas y la información científica relevante, dejando luego al proceso democrático el papel de tomar la decisión. Los otros tres roles, al limitar el rango aparente de opciones disponibles, no contribuyen tan positivamente al proceso democrático, y uno de ellos es abiertamente dañino: el del activista o lobista encubierto, no porque la politización sea mala en sí, sino porque lo es cuando se la trata de ocultar tras el prestigio de una supuesta objetividad científica.

Este énfasis en la importancia de discutir primero las posibles vías de acción antes de decidir sobre sus méritos relativos nos recuerda el artículo en el que John Platt (Science 146: 347-353; 1964) plantea fervientemente la necesidad de generar más de una hipótesis como explicación de cada fenómeno bajo estudio; su propuesta apunta a evitar quedar encandilado con una hipótesis, frecuentemente sobrevalorada por ser propia, para acelerar el proceso de descartarla si es inviable para seguir avanzando. El símil entre este ejemplo de la ciencia básica y lo que se espera de los proveedores de alternativas no es perfecto, pero enfatiza lo que Pielke propone como solución para los obstáculos que se dan en política, y en el que los científicos pueden y deben ayudar, a través de su creatividad entrenada en el juicio crítico, para destrabar los conflictos. En otras palabras: la ciencia no debería verse como algo que debe ser mantenido separado, puro, a salvo de la política, sino como un recurso clave para facilitar las difíciles decisiones que la sociedad debe enfrentar a la luz de los valores, intereses e incluso visiones científicas contrapuestas. Hay un papel de la ciencia en la política, y el modelo a seguir es el de proponente de alternativas.

Uno de los méritos del texto es que su planteo general queda claro luego de haber leído sólo los tres primeros capítulos (son 9 en total). Los tres siguientes profundizan sobre los conceptos de valores (capítulo 4), incertidumbre (capítulo 5), y las consecuencias de las políticas científicas (capítulo 6), con este último avanzando sobre el modelo lineal y sus alternativas. Los dos siguientes (capítulos 7 y 8 ) analizan dos casos contrastantes de vinculación entre la generación de información y la acción política. Éstos son la decisión de EEUU de atacar Irak bajo el argumento de la 'Guerra Preventiva', y la polémica generada por la publicación del libro 'El Ambientalista Escéptico', 2001, de Bjørn Lomborg. El capítulo final resume las conclusiones en forma de una guía práctica para el uso de los científicos que quieran mejorar sus vínculos con los ámbitos de decisión. Finalmente, un apéndice usa el marco propuesto para analizar más brevemente otros cinco casos variados e ilustrativos, casi todos ellos de los EEUU y el Reino Unido.

En nuestra opinión, el libro representa un material extremadamente útil como base de un debate necesario en el campo de las ciencias relacionadas con el ambiente, incluyendo los referidos a la producción agropecuaria. El planteo elegante y claro de los caminos que un científico puede seguir, planteados en la primera mitad del libro, se vuelve algo imperfecto cuando se 'baja a tierra' el mensaje en la segunda mitad. Esta imperfección, sin embargo, remarca lo difícil e importante que es ser explícito respecto a las responsabilidades y estrategias de interacción de la ciencia ante la sociedad, y deja abierto el debate, ahora con mejores elementos y conceptos. Por tratarse de un texto en inglés, podría pensarse que sólo sería accesible a investigadores y para el nivel de posgrado, pero su brevedad y estilo lo hacen también útil para cursos avanzados de grado, complementándolo por ejemplo con el análisis de casos de interés local, nacional o regional relevantes para la carrera y nivel de los alumnos, como podrían ser los agroquímicos o el uso de la tierra y el ordenamiento territorial. Tanto para el profesional de las áreas técnicas como para ciudadanos interesados en entender y participar de las decisiones que los conciernen, esta obra incita a la reflexión, como mínimo proveyendo una lente para analizar las actitudes propias y las posiciones ajenas. Lo que no es poco.

Esteban G. Jobbágy, IMASL, UNSL, y Roberto J. Fernández, IFEVA-FAUBA Contacto: jobbagy @unsl.edu.ar - fernandez@agro.uba.ar 